\title{
Regulation of Cochlear Fluids pH: (II) The Role of Bicarbonate
}

\author{
Masaaki Suzuki*, Tadashi Wakayama and Ryosuke Kotani \\ Department of Otolaryngology, Teikyo University Chiba Medical Center, Chiba, Japan
}

\begin{abstract}
Bicarbonate provides the dominant $\mathrm{pH}$ buffer of the cochlear fluids. In the present study, perilymph bicarbonate concentration was manipulated during which endocochlear potential, cochlear fluids $\mathrm{pH}$ and cochlear sensitivity to sounds were monitored. Perilymphatic perfusion of medium containing elevated $\mathrm{HCO}_{3}^{-}$, at higher $\mathrm{pH}$ than normal, produced a decrease in endolymph $\mathrm{pH}$. Similarly, perfusion of nominally $\mathrm{HCO}_{3}{ }^{-}$-free solution, with lower $\mathrm{pH}$ than normal, produced an increase in endolymph $\mathrm{pH}$. When $\mathrm{pH}$ changes were induced with HEPES-buffered media, endolymphatic and perilymphatic $\mathrm{pH}$ changed in the same direction. The observed endolymph $\mathrm{pH}$ changes induced by perilymphatic $\mathrm{HCO}_{3}{ }^{-}$manipulations therefore depend on $\mathrm{HCO}_{3}{ }^{-}$, rather than $\mathrm{pH}$ changes. These findings can be explained by the generation of localized changes of $\mathrm{CO}_{2}$ in the cochlear fluids associated with bicarbonate homeostasis. These data demonstrate some key properties of the $\mathrm{CO}_{2} / \mathrm{HCO}_{3}{ }^{-}$buffer system and suggest the likely role for carbonic anhydrase in tissues of the lateral wall. In practical terms, the data also suggest that the $\mathrm{pH}$ stability of inner ear fluids cannot be adequately maintained when bicarbonate-altered media are perfused, especially when $\mathrm{pH}$ buffers other than $\mathrm{HCO}_{3}{ }^{-}$are used.
\end{abstract}

Keywords: Cochlear fluids $\mathrm{pH}$, endocochlear potential, perilymph bicarbonate.

\section{INTRODUCTION}

Although it is known that cochlear fluids $\mathrm{pH}$ is dominated by the $\mathrm{CO}_{2} / \mathrm{HCO}_{3}{ }^{-}$buffer system, there are only limited data on the characteristics of $\mathrm{pH}$ regulation in the cochlea and no systematic studies of how cochlear fluids $\mathrm{pH}$ depends on $\mathrm{HCO}_{3}{ }^{-}$level. In a previous study, it was shown that the $\mathrm{pH}$ of cochlear fluids depended on respiratory $\mathrm{CO}_{2}$ status. Elevation of arterial $\mathrm{CO}_{2}$ (as indicated by end-tidal $\mathrm{CO}_{2}$ measurement) produced acidification of endolymph and perilymph, in accordance with the known $\mathrm{CO}_{2}$-dependence of the $\mathrm{HCO}_{3}{ }^{-}$buffer system (reviewed by Hruska [1]). In the present study, we have investigated the influence of changes in $\mathrm{HCO}_{3}{ }^{-}$concentration, while carefully maintaining a stable respiratory $\mathrm{CO}_{2}$ status. In any solution, changes of $\mathrm{HCO}_{3}{ }^{-}$ concentration result in $\mathrm{pH}$ changes, with $\mathrm{pH}$ increasing as $\mathrm{HCO}_{3}{ }^{-}$is increased [2]. The $\mathrm{HCO}_{3}{ }^{-}$concentration in cochlear fluids is difficult to measure directly, since it was found that $\mathrm{HCO}_{3}{ }^{-}$ion exchangers available for ion-selective electrodes are far more selective for carbonate than $\mathrm{HCO}_{3}^{-}$[3]. For cochlear perfusion, many groups use a medium similar to that described by Konishi and Kelsey [4], containing $12 \mathrm{mM}$ $\mathrm{HCO}_{3}{ }^{-}$, which is well below the presumed normal physiologic level of 20 to $25 \mathrm{mM}$ in guinea pigs [5, 6]. A few investigators have used perfusion media incorporating non- $\mathrm{HCO}_{3}^{-}$buffers and low $\mathrm{HCO}_{3}{ }^{-}$content. Since $\mathrm{HCO}_{3}^{-}$ represents approximately $20 \%$ of the anion content of endolymph, homeostasis of $\mathrm{HCO}_{3}{ }^{-}$likely plays a significant role in maintaining normal endolymph status. $\mathrm{HCO}_{3}{ }^{-}$ion

*Address correspondence to this author at the Department of Otolaryngology, Teikyo University Chiba Medical Center, 3426-3, Anesaki, Ichihara, Chiba, 299-0111, Japan; Tel: +81-436-62-1211;

Fax: +81-436-61-8474; E-mail: suzukima@med.teikyo-u.ac.jp movements are likely to contribute directly to composition, osmolarity and volume changes of endolymph during experimental treatments or pathologic situations. In addition, $\mathrm{pH}$ changed associated with $\mathrm{HCO}_{3}{ }^{-}$disturbances are likely to modulate the transport of other ions, such as the transport of $\mathrm{K}^{+}$into endolymph [7].

\section{METHODS}

This study used 19 pigmented guinea pigs weighing 300$500 \mathrm{~g}$, anesthetized with a combination of sodium pentobarbital $(25 \mathrm{mg} / \mathrm{kg}$ i.p.) and Innovar-Vet (O.35 mllkg Lm.). (InnovarVet contains $0.4 \mathrm{mg} / \mathrm{ml}$ fentanyl and 20 $\mathrm{mg} / \mathrm{ml}$ droperidol). Sodium pentobarbital was supplemented as required to maintain deep surgical anesthesia via an intravenous line in the left external jugular vein. Body temperature was maintained at $38-39{ }^{\circ} \mathrm{C}$ with a thermistor-controlled heating pad. The trachea was cannulated and, prior to recordings, animals were immobilized with gallamine triethiodide $(2-3 \mathrm{mg} / \mathrm{kg})$ and artificially ventilated. Expired $\mathrm{CO}_{2}$ was monitored using a Puritan-Bennett Datex $\mathrm{CO}_{2}$ analyzer, designed for use with small ventilation volumes and equipped with peak-hold circuitry. Throughout the recording period, end-tidal respiratory $\mathrm{CO}_{2}$ was maintained close to $5 \%(38 \mathrm{~mm} \mathrm{Hg})$ by periodically adjusting the tidal volume of the respirator as necessary. The head of the animal was secured in a rigid head-holder and the right cochlea was exposed by a ventrolateral approach.

The method and the recording system for the microelectrodes have been described elsewhere [8]. In brief, all measurements of endolymph were made in the second cochlear tum through small access fenestras made in the lateral wall. The fenestras, which were 30 to 50 micrometers in diameter were made with a fine pick after first thinning the bone with a flap knife. In the case of endolymphatic 
measurements, endocochlear potential (EP) was recorded from the reference barrel of the ion electrode. The $\mathrm{pH}$ of endolymph and scala vestibuli perilymph were measured by double-barreled $\mathrm{pH}$-selective electrodes. Double-barreled electrodes were made from borosilicate capillary and one barrel was silanized by exposure to dimethyldichlorosilane (Sigma, St. Louis, USA) vapor and the tip was broken to 2-3 micrometers in diameter. The ion barrel of electrodes was filled with $40 \mathrm{mM} \mathrm{KH}_{2} \mathrm{PO}_{4}, 23 \mathrm{mM} \mathrm{NaOH}$ and $15 \mathrm{mM} \mathrm{NaCl}$ [9] and the potential barrel was filled with $500 \mathrm{mM} \mathrm{KCl}$. The pH-sensitive exchanger for this electrode was Fluka 95297 (Fluka Chemical, Ronkonkoma, NY, USA), a small column of which was drawn into the ion barrel by suction. All electrodes were calibrated before and after use in commercially available buffer solutions at $\mathrm{pH} 8.00, \mathrm{pH} 7.00$ and $\mathrm{pH} 6.00$ (Fisher Scientific, Pittsburgh, PA, USA) at $38^{\circ} \mathrm{C}$. The mean response slope of the $\mathrm{H}^{+}$electrodes used in this study was $50.5 \mathrm{mV} /$ decade (SD 1.66, $\mathrm{n}=29$ ). Potentials were recorded from ion electrodes under computer control using digital meters equipped with IEEE-488 interfaces.

The perilymphatic space was perfused with solution at a rate of $5 \mathrm{microliter} / \mathrm{min}$. Perfusate entered the basal tum of scala tympani through a double-barreled pipette. A bead of paint on the perfusion pipette provided a gasket to minimize leakage at the injection site One Perfusion Pump (Harvard model PHD 2000) and one perfusion pipette barrel was used for each solution perfused. The outlet for perfusate was made in the basal tum of scala vestibuli. Accumulating fluid was continually removed from the bulla by a suction tubing placed behind the cochlear apex. The composition of solutions perfused are given in Table 1. Solutions were $\mathrm{pH}$ buffered with either $\mathrm{HCO}_{3}{ }^{-}$or HEPES. For each individual experiment, all perfusions utilized the same buffer and a maximum of two treatments were performed. The osmolarity of these solutions was $292-295$ mOsm. All solutions were pre-equilibrated with $\mathrm{CO}_{2}$ by bubbling with $5 \% \mathrm{CO}_{2}$ in air for 20 min prior to perfusion. After bubbling, the $\mathrm{pH}$ of the $\mathrm{HCO}_{3}^{-}$buffered control medium was averaged 7.29 (SD $0.08, \mathrm{n}=9$ ). HEPES-buffered control medium was adjusted to $\mathrm{pH} 7.4$.

Whole nerve action potential (AP) thresholds were monitored from an $\mathrm{Ag} / \mathrm{AgCl}$ ball electrode placed on the otic capsule close to the round window membrane. AP thresholds were tracked throughout the experiment using an automated procedure according to procedures detailed in Salt and Vora [10]. For each threshold measure, stimulus level was increased in $10 \mathrm{~dB}$ steps until a suprathreshold response was detected, and then decreased in $5 \mathrm{~dB}$ steps until the response amplitude fell below the threshold value. Interpolation was used to establish the sound level at which a response of criterion amplitude would have been generated. For this study, a 20 microvolt criterion was used to establish threshold, which is a higher criterion than we normally use to ensure that responses could be clearly resolved during periods of perfusion.

Data are presented as the mean and the standard deviation (SD) of the number ( $\mathrm{n}$ ) of observations given. All statistical analysis was performed using the Statistical Package for Social Science, version 11.01 (SPSS Inc., Chicago, IL). The study procedures were in accordance with the standards set forth in the eighth edition of Guide for the Care and Use of Laboratory Animals published by the National Academy of Sciences, The National Academies Press, Washington, DC, USA.

\section{RESULTS}

One issue which this study had to deal with was that cochlear perfusion with control solutions induced systematic changes of cochlear fluid $\mathrm{pH}$ and EP in the second turn, and of AP threshold sensitivity. The changes induced by the onset of perfusion with $\mathrm{HCO}_{3}{ }^{-}$-buffered or HEPES-buffered control solutions are summarized in Fig. (1). With $\mathrm{HCO}_{3}{ }^{-}$ buffered medium, endolymph $\mathrm{pH}$ was always increased by the perfusion, the mean increase being $0.10($ SD $0.08, n=9)$. The $\mathrm{pH}$ measured in SV typically underwent a slight initial decrease, followed by an increase which averaged 0.09 (SD $0.05, \mathrm{n}=5$ ). EP showed a characteristic decrease at the onset of perfusion, followed by a slow increase and AP thresholds were raised by approximately $10 \mathrm{~dB}$.

With the onset of perfusion of HEPES-buffered control medium, endolymph $\mathrm{pH}$ changes were significantly larger than those with $\mathrm{HCO}_{3}^{-}$-buffer (Anova, $p<0.05$ ). With HEPES-buffered solution, endolymph $\mathrm{pH}$ increased by a mean value of $0.22(+/-0.12, n=9)$. Perilymphatic $\mathrm{pH}$ changes were markedly different with HEPES compared with $\mathrm{HCO}_{3}^{-}$buffer. With HEPES, perilymph $\mathrm{pH}$ showed a rapid acidification to a value well below that of the perfusate

Table 1. Composition of solutions perfused in this study.

\begin{tabular}{|c|c|c|c|c|}
\hline Component (mM) & $\begin{array}{c}\text { Normal, Bicarbonate- } \\
\text { Buffered }\end{array}$ & HEPES-Buffered & $\begin{array}{l}\mathrm{Hig}-\mathrm{HCO}_{3}^{-} \\
(50 \mathrm{mM})\end{array}$ & $\begin{array}{c}\text { Low-HCO }_{3} \\
\quad(0 \mathrm{mM})\end{array}$ \\
\hline $\mathrm{NaCl}$ & 122 & 142 & 97 & 147 \\
\hline $\mathrm{KCl}$ & 3.5 & 3.5 & 3.5 & 3.5 \\
\hline $\mathrm{NaHCO}_{3}$ & 25 & 0 & 50 & 0 \\
\hline $\mathrm{CaCl}_{2}$ & 1.3 & 1.3 & 1.3 & 1.3 \\
\hline $\mathrm{NaH}_{2} \mathrm{PO}_{4}$ & 0.75 & 0.75 & 0.75 & 0.75 \\
\hline D-glucose & 11 & 1 & 11 & 11 \\
\hline Na-HEPES & - & 5 & - & - \\
\hline
\end{tabular}



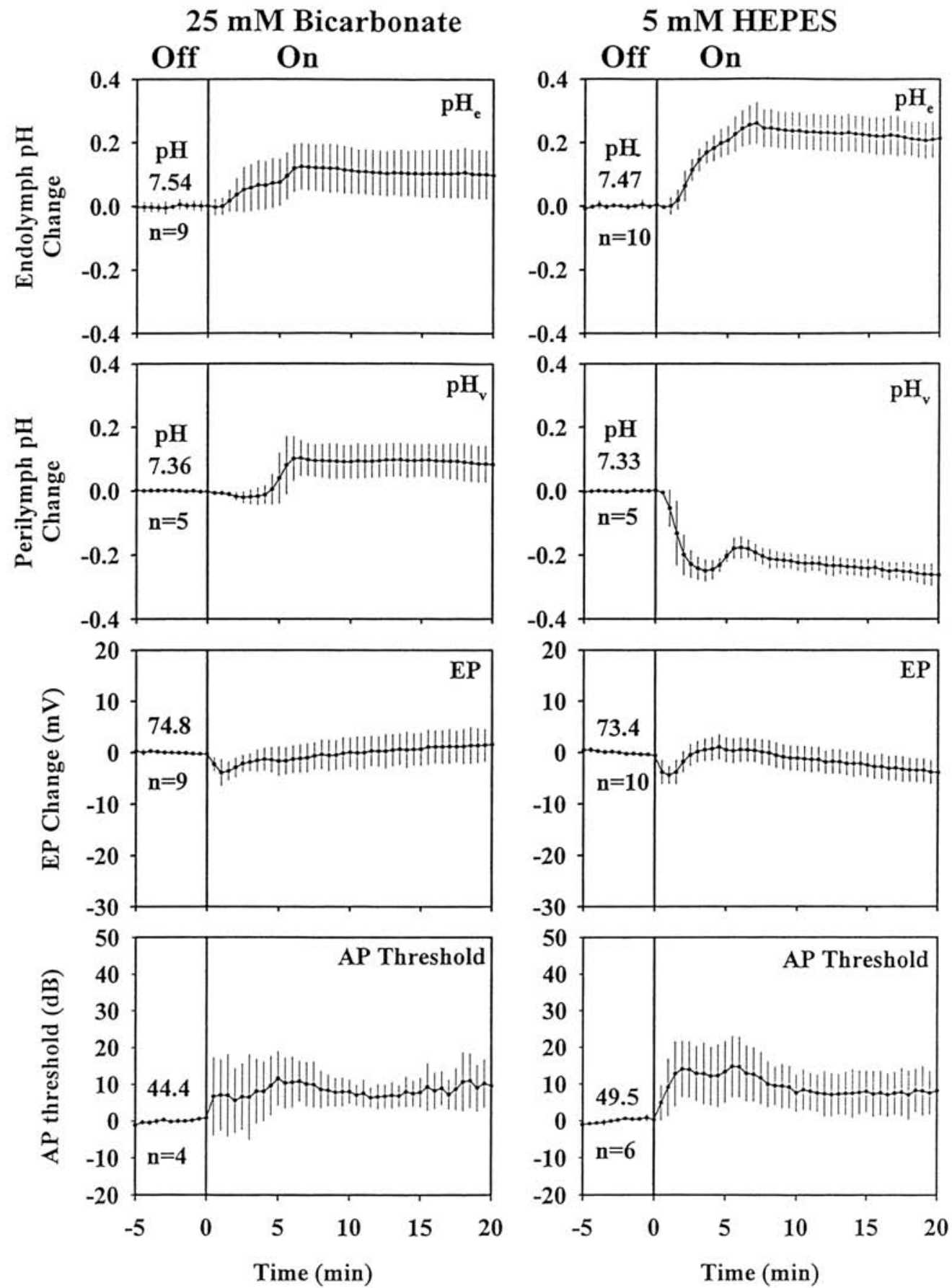

Fig. (1). Effects of perfusion onset with bicarbonate $\left(\mathrm{HCO}_{3}{ }^{-}\right)$or HEPES-buffered $\left(\mathrm{HCO}_{3}{ }^{-}\right.$-free) media on endolymph pH, scala vestibuli perilymph $\mathrm{pH}$, endocochlear potential (EP) and cochlear action potential (AP) thresholds in response to $8 \mathrm{kHz}$ tone bursts. The heavy vertical line at zero time indicates perfusion onset. The average baseline value and the number of experiments included in the average are indicated. Bars indicate the standard deviation of the mean value.

and the acidification was sustained throughout the perfusion. A notable difference between the effects of $\mathrm{HCO}_{3}^{-}$and HEPES solutions, was that for $\mathrm{HCO}_{3}^{-}$endolymphatic and perilymphatic $\mathrm{pH}$ changes were not significantly different (Anova, $p>0.5$ ) while for HEPES-buffered solution the endolymphatic changes were significantly greater than those 
seen in perilymph (Anova, $p<0.05$ ). In terms of functional changes, the EP tended to decline with HEPES-buffered solution, compared to the slow increase seen with $\mathrm{HCO}_{3}{ }^{-}$. The EP at the end of the perfusion period was significantly lower for the HEPES-buffer (t-test, $p=0.003$ ). In contrast, the AP threshold elevations were not significantly different during perfusion of HEPES and $\mathrm{HCO}_{3}{ }^{-}$buffered solutions. The $\mathrm{pH}$ changes induced by control perfusions are thought to be at least partially induced by mechanical disturbances. We therefore minimized mechanically-induced effects by continually perfusing the cochlea and switching solutions between control and altered media. The effects of varying $\mathrm{HCO}_{3}{ }^{-}$concentration by this paradigm are summarized in Fig. (2). For a nominally $\mathrm{HCO}_{3}{ }^{-}$-free solution, which was only buffered to a small extent by $\mathrm{PO}_{4}^{-}$, the $\mathrm{pH}$ measured after $\mathrm{CO}_{2}$ equilibration averaged $4.25(\mathrm{SD} 0.4, \mathrm{n}=4)$. When low- $\mathrm{HCO}_{3}{ }^{-}$solution was perfused (Fig. 2, left panels), perilymph $\mathrm{pH}$ was reduced, as expected, but endolymph $\mathrm{pH}$ was found to increase. EP showed a transient increase and AP threshold changes were not remarkable. Induced changes were reversible on return to $25 \mathrm{mM} \mathrm{HCO}_{3}^{-}$The $\mathrm{pH}$ of the elevated $\mathrm{HCO}_{3}{ }^{-}(50 \mathrm{mM})$ solution averaged $7.58(\mathrm{SD} 0.1, \mathrm{n}=$
5) after $\mathrm{CO}_{2}$ equilibration. With elevated- $\mathrm{HCO}_{3}{ }^{-}$perfusion, perilymph $\mathrm{pH}$ was increased but endolymph $\mathrm{pH}$ decreased. Associated with the acidification of endolymph, EP was systematically decreased and AP thresholds were elevated. In an attempt to establish the origins of $\mathrm{HCO}_{3}^{-}$-induced endolymphatic changes, we induced similar $\mathrm{pH}$ changes. while maintaining $\mathrm{HCO}_{3}{ }^{-}$level unchanged. The results of $\mathrm{pH}$ changes induced by nominally $\mathrm{HCO}_{3}{ }^{-}$-free, HEPES-buffered solutions, are shown in Fig. (3). Solutions were perfused at $\mathrm{pH} 6.0$ and 8.0, values intended to generate comparable perilymphatic $\mathrm{pH}$ change. Perfusion of solution with $\mathrm{pH} 6$ resulted in decreases in both perilymph and endolymph $\mathrm{pH}$, a result which is quite different from when $\mathrm{pH}$ change was induced by $\mathrm{HCO}_{3}^{-}$manipulation. Associated with the acidification of endolymph was a decrease in EP and an elevation of AP thresholds. Perfusion of HEPES-buffered solution at $\mathrm{pH} 8.0$ increased the $\mathrm{pH}$ measured in perilymph and endolymph, although the measured changes were smaller than anticipated due to the acidification of perilymph associated with HEPES-buffered perfusion. The $\mathrm{pH}$ elevations had only minor effects on EP and AP thresholds.
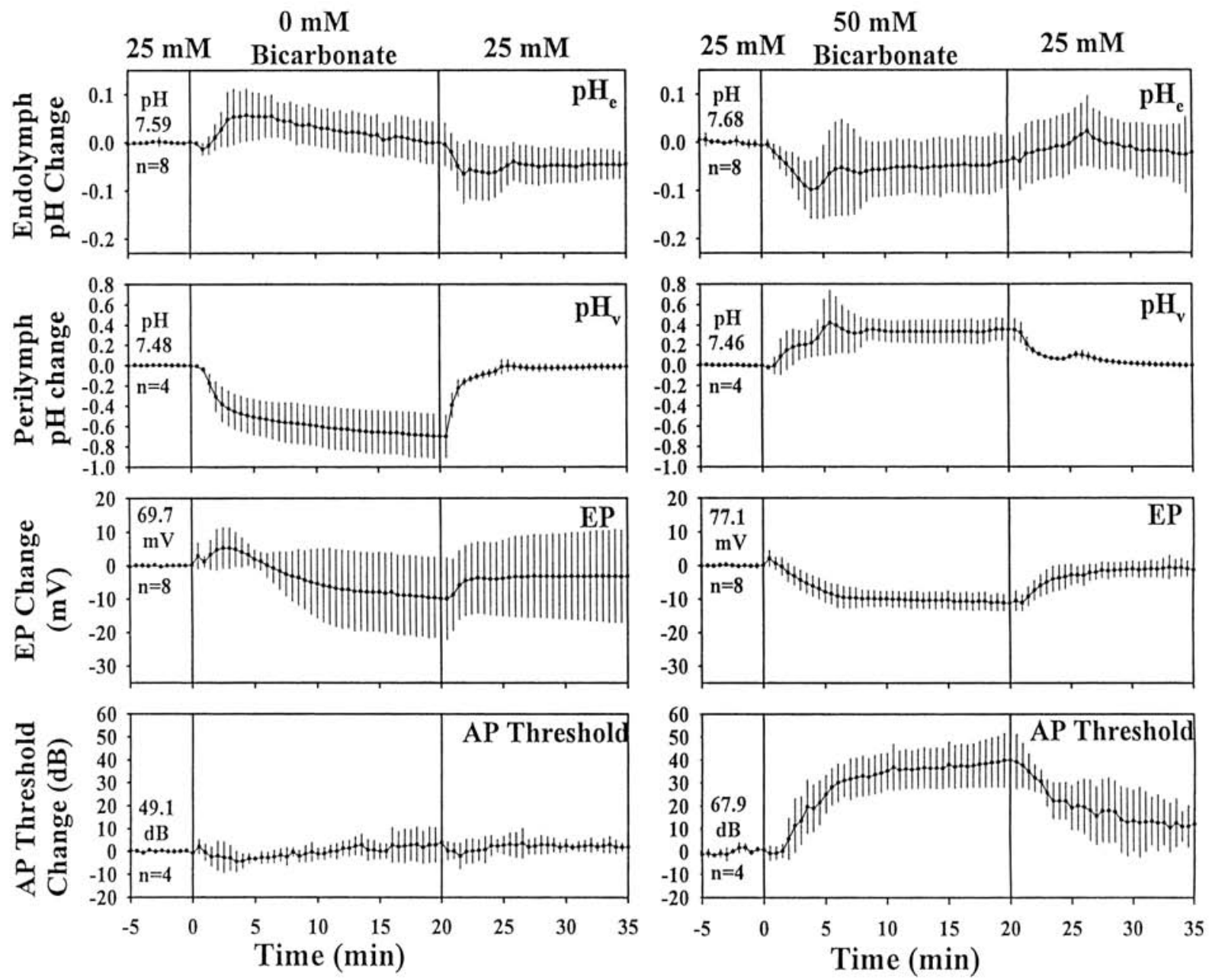

Fig. (2). Effect of perilymphatic bicarbonate $\left(\mathrm{HCO}_{3}{ }^{-}\right)$changes on the cochlear $\mathrm{pH}$ and tone-evoked cochlear responses. Vertical lines indicate the beginning and end of perfusion with solution containing nominally $0 \mathrm{mM} \mathrm{HCO}_{3}^{-}$(left side) or $50 \mathrm{mM} \mathrm{HCO}_{3}{ }^{-}$(right side). Bars indicate standard deviation. In the periods before and after perfusion with the specified solution, the cochlea was perfused with a control solution containing $25 \mathrm{mM} \mathrm{HCO}_{3}{ }^{-}$. Perfusion with altered- $\mathrm{HCO}_{3}{ }^{-}$solutions produced oppositely-directed $\mathrm{pH}$ changes in endolymph and perilymph. 

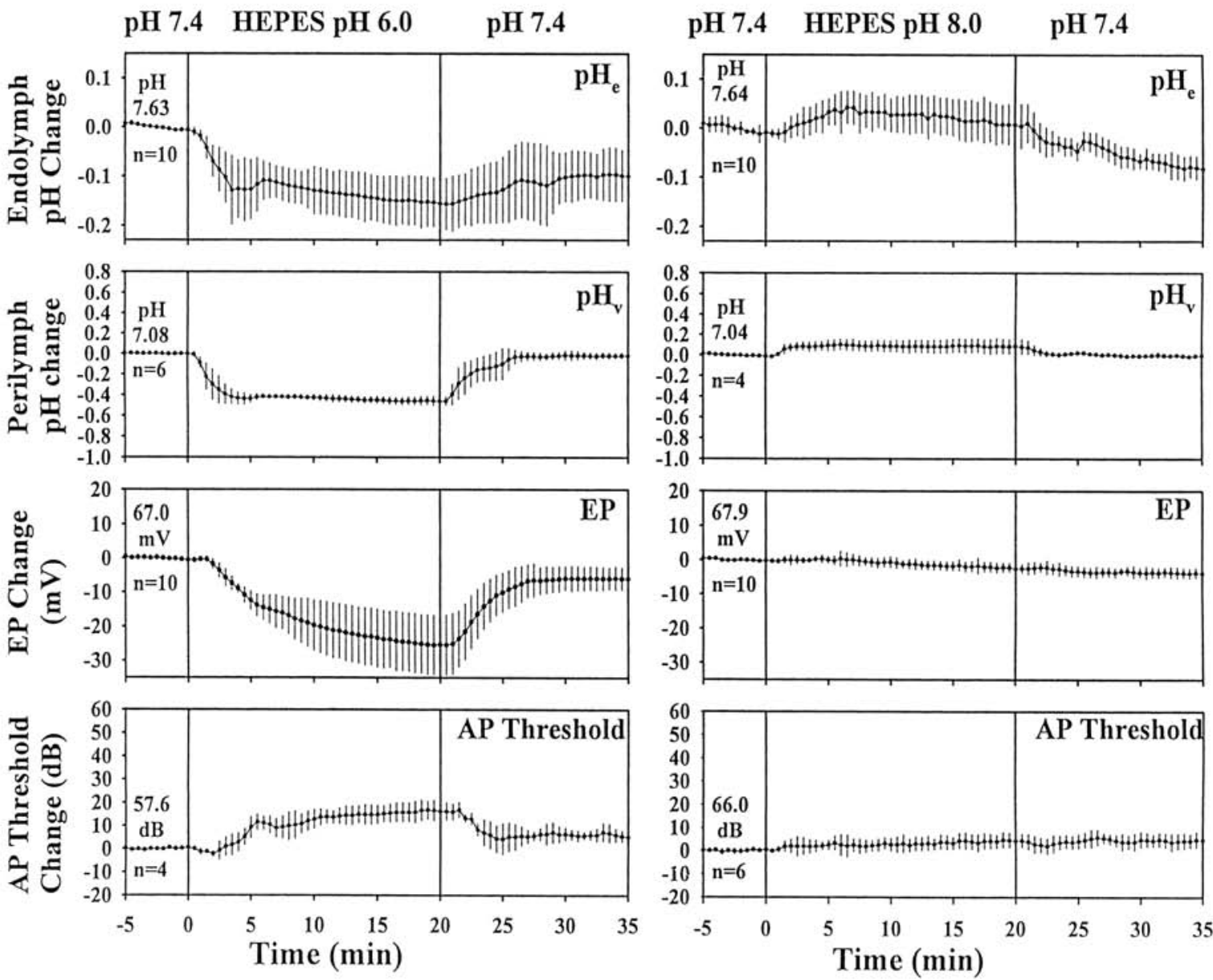

Fig. (3). Effect of perilymphatic $\mathrm{pH}$ changes induced by HEPES-buffered $\left(\mathrm{HCO}_{3}{ }^{-}\right.$-free) media at $\mathrm{pH} 6.0$ (left) or $\mathrm{pH} 8.0$ (right). $\mathrm{Baseline}$ values of each parameter and the number of experiments are given for each curve. Bars indicate standard deviation.

The differences between endolymph and perilymph $\mathrm{pH}$ changes induced by $\mathrm{HCO}_{3}{ }^{-}$and HEPES-buffered solutions are summarized in Fig. (4). Values are the $\mathrm{pH}$ change averaged over the time period from 2 to 10 minutes after the start of the altered-composition perfusate. For the $\mathrm{HCO}_{3}{ }^{-}$ buffer, endolymph and perilymph $\mathrm{pH}$ changes were consistently oppositely directed. In contrast, for the HEPES buffered solutions, endolymphatic $\mathrm{pH}$ changes were similarly-directed, though smaller than those induced in perilymph.

\section{DISCUSSION}

An interesting finding of this study was that endolymph $\mathrm{pH}$ changes were induced by $\mathrm{HCO}_{3}{ }^{-}$manipulations which were oppositely-directed to those measured in perilymph. This occurred only when $\mathrm{HCO}_{3}{ }^{-}$concentration changed, but not when comparable $\mathrm{pH}$ changes were induced under constant, $\mathrm{HCO}_{3}^{-}$-free conditions. The oppositely-directed endolymphatic $\mathrm{pH}$ change with perilymphatic $\mathrm{HCO}_{3}{ }^{-}$ manipulation must therefore result from the $\mathrm{HCO}_{3}{ }^{-}$, rather than the $\mathrm{pH}$ change. This finding cannot be explained by a mechanism of perilymphatic $\mathrm{pH}$ homeostasis mediated by acid or $\mathrm{HCO}_{3}{ }^{-}$transport between endolymph and perilymph. In this case, where ions are simply transported, the $\mathrm{pH}$ changes in endolymph and perilymph should be in the same direction. On the other hand, the observations are readily explained if mechanisms likely to underlie $\mathrm{HCO}_{3}{ }^{-}$ homeostasis are considered. In the case of a reduction in $\mathrm{HCO}_{3}{ }^{-}$, the equilibrium between $\mathrm{CO}_{2}$ and $\mathrm{HCO}_{3}{ }^{-}$, catalyzed by carbonic anhydrase, will be skewed in the direction whereby $\mathrm{CO}_{2}$ will be converted to $\mathrm{HCO}_{3}{ }^{-}$and $\mathrm{H}^{+}$. This would result in a decrease in the steady-state $\mathrm{CO}_{2}$ level in the perilymph. Since $\mathrm{CO}_{2}$ readily passes through membranous boundaries, this would in tum decrease the $\mathrm{CO}_{2}$ level in endolymph, thereby resulting in an alkalinization. Similarly, in the elevated $\mathrm{HCO}_{3}^{-}$condition, the restoration of normal $\mathrm{HCO}_{3}{ }^{-}$by the addition of acid, would result in a release of $\mathrm{CO}_{2}$ and subsequent acidification of endolymph. This explanation is consistent with our previous study in which endolymph $\mathrm{pH}$ was shown to be highly sensitive to the prevailing $\mathrm{CO}_{2}$ level [2]. It can be calculated that a relatively small $\mathrm{CO}_{2}$ change, such as a reduction from $5 \%$ to $4 \%$ (i.e. a change of $7.6 \mathrm{mmHg}$ ), would be sufficient to induce the measured endolymph $\mathrm{pH}$ changes, if we can assume that endolymph $\mathrm{HCO}_{3}^{-}$remains constant. Endolymph $\mathrm{HCO}_{3}{ }^{-}$ cannot be readily measured by ion-selective electrode as the commercially-available exchanger which was marketed as $\mathrm{HCO}_{3}{ }^{-}$-selective has now been shown to be preferentially 

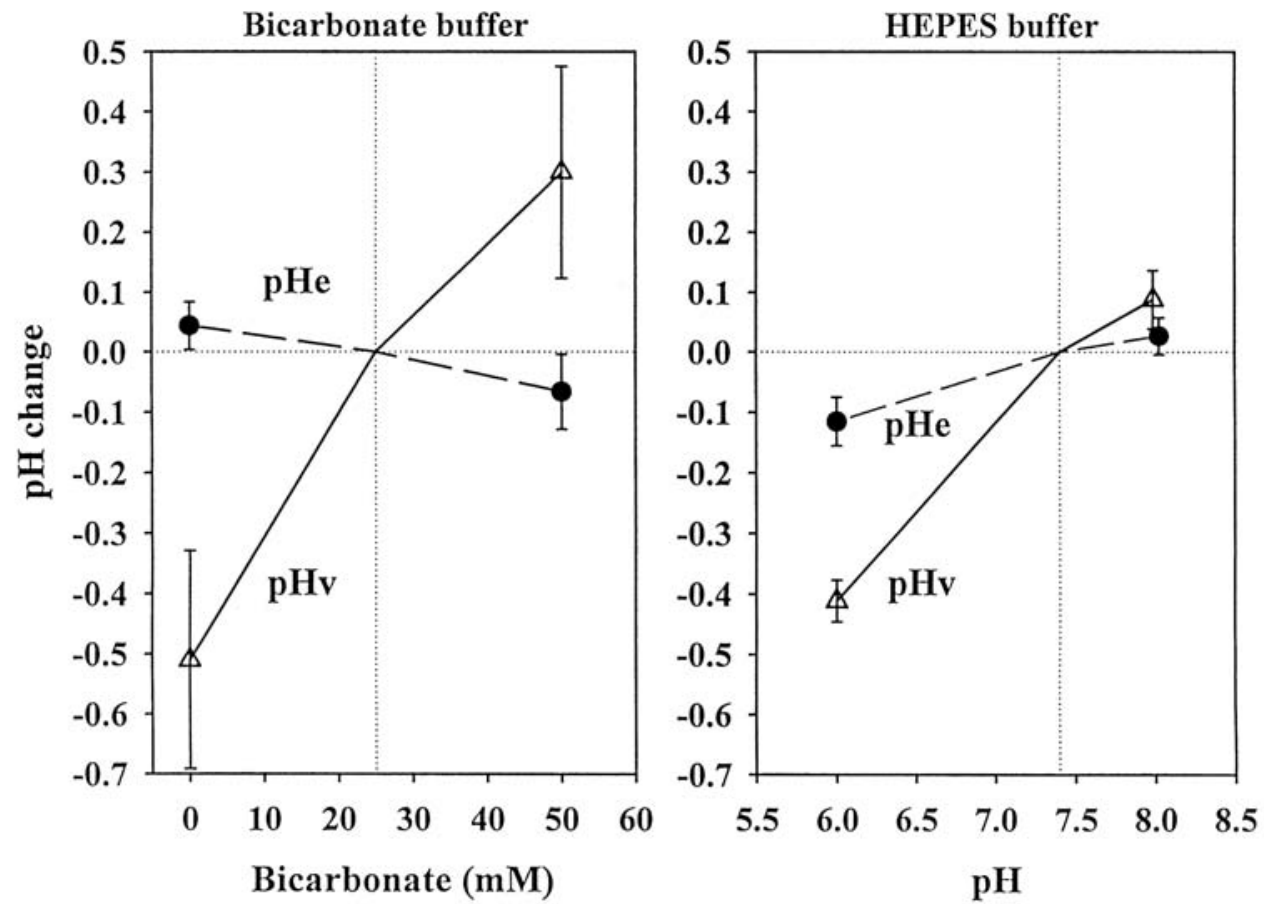

Fig. (4). Summary of endolymphatic $\left(\mathrm{pH}_{\mathrm{e}}\right.$, dotted lines) and perilymphatic $\left(\mathrm{pH}_{\mathrm{v}}\right.$, solid lines) $\mathrm{pH}$ changes induced when $\mathrm{HCO}_{3}{ }^{-}$-buffered or HEPES-buffered $\left(\mathrm{HCO}_{3}{ }^{-}\right.$-free) media are perfused. Data points are the $\mathrm{pH}$ values averaged over the time period from 2 to 10 minutes after perfusion onset. With $\mathrm{HCO}_{3}^{-}$buffers, endolymphatic $\mathrm{pH}$ changes are oppositely directed to those induced in perilymph. With HEPESbuffered media, endolymphatic anc perilymphatic $\mathrm{pH}$ changes are in the same direction. The number of measurements in each condition are shown in Figs. $(\mathbf{2}, \mathbf{3})$.

selective to carbonate $\left(\mathrm{CO}_{3}{ }^{2-}\right)$ and may thus give misleading results $[3,11]$. The technique of cochlear perfusion is widely regarded as benign, in which control perfusions of the perilymphatic space are believed to have little influence on cochlear function. This impression has partly arisen because many investigators have not measured function during perfusion, but instead make measurements some time after perfusion ends [12-14]. In studies where cochlear responses are measured during perfusion, small decreases in soundinduced responses (cochlear microphonic or action potential amplitudes) and fluctuations of the endocochlear potential are generally observed [4, 15]. The EP changes and AP thresholds we observed at the onset of control $(25 \mathrm{mM})$, $\mathrm{HCO}_{3}$-buffered solution are consistent with these previously-published findings. We have further found that significant disturbance of cochlear fluids $\mathrm{pH}$ occurs with perfusion. With $\mathrm{HCO}_{3}{ }^{-}$-buffered media, we systematically observed a substantial alkalinization of endolymph in the second turn at the onset. With HEPES-buffered solution, the alkalinization of endolymph was even greater, even though perilymph became progressively more acidotic with time. The marked acidosis of perilymph is consistent with a high rate of acid generation, presumably derived from $\mathrm{CO}_{2}$, in which $\mathrm{HCO}_{3}{ }^{-}$and $\mathrm{H}^{+}$are generated in equimolar quantitites. Similarly, the marked elevation of endolymph $\mathrm{pH}$ with HEPES-buffered perfusion onset is a consequence of the mechanisms compensating for the reduced $\mathrm{HCO}_{3}{ }^{-}$reducing the available $\mathrm{CO}_{2}$ as discussed above. One conclusion from these observations is that it is not feasible to maintain $\mathrm{pH}$ stability of the inner ear in vivo when $\mathrm{HCO}_{3}{ }^{-}$-free solutions are employed.

There are a number of possible origins of perfusioninduced $\mathrm{pH}$ changes. One likely factor is a perfusion-induced mechanical disturbance of the cochlear partition, influencing currents passing through the boundary tissues and thereby affecting ion movements [16]. Salt \& DeMott have demonstrated that perilymphatic perfusion at $5 \mathrm{ul} / \mathrm{min}$ induces a sustained basally-directed displacement of endolymph by approximately $0.4 \mathrm{~mm}$, which only returns when perfusion ceases [17]. If the displacement of tissues is sustained throughout the perfusion, as these data suggest, it is likely that sustained changes in ion transport would be induced. The possibility thus exists that-mechanical disturbance may affect ion transport, giving rise to $\mathrm{pH}$ changes which in vitro studies have demonstrated may in turn give rise to further ion transport changes [7].

An important conclusion from these studies is that the $\mathrm{pH}$ of cochlear fluids does not appear to be tightly regulated by the tissues responsible for endolymph and perilymph homeostasis. The high mobility of $\mathrm{CO}_{2}$ across tissue boundaries would limit the degree of local control of $\mathrm{pH}$ in extracellular compartments. In contrast, our results suggest that $\mathrm{HCO}_{3}{ }^{-}$homeostasis appears to be of high importance in the intact ear, which would indirectly lead to $\mathrm{pH}$ regulation. Since $\mathrm{HCO}_{3}{ }^{-}$plays a significant role as a component of endolymph and perilymph, maintenance of fluid $\mathrm{HCO}_{3}{ }^{-}$may accomplish both electrolyte and $\mathrm{pH}$ homeostasis. 
In consideration of the EP changes associated with $\mathrm{HCO}_{3}{ }^{-}$and $\mathrm{pH}$ manipulations, the two treatments which acidified endolymph $\left(50 \mathrm{mM} \mathrm{HCO}_{3}{ }^{-}\right.$, HEPES at $\mathrm{pH}$ 6) produced immediate decreases of EP, while treatments which alkalinized endolymph produced no change or small increases in EP. These findings contrast with those induced by $\mathrm{CO}_{2}$ manipulations in our prior study in which an elevation of $\mathrm{CO}_{2}$ caused acidosis of cochlear fluids and an increase in EP [2]. In the vascular-perfused preparation, Arakawa et al. found EP to be relatively insensitive to vascular $\mathrm{HCO}_{3}^{-}$changes, but highly sensitive to vascular $\mathrm{CO}_{2}$ changes [18]. Low $\mathrm{CO}_{2}$ tensions induced EP decreases and high $\mathrm{CO}_{2}$ tensions induced transient EP increases followed by a decline. In the present, perilymphaticallyperfused preparation, tissues closely associated with the vascular compartment, such as marginal cells, are less likely to be affected by the experimental manipulations. The study of Wangemann et al. found that vestibular dark cells were significantly more sensitive to $\mathrm{pH}$ changes applied to the basolateral side compared to the apical side of the epithelium [7]. Thus, it is likely that the difference between experimental findings arises from different tissues being affected by the experimental treatments. This is consistent with there not being a single cell type (such as the marginal cells) involved in EP generation which is $\mathrm{CO}_{2}$-sensitive, but rather multiple cell types, each with degrees of $\mathrm{pH}$ or $\mathrm{CO}_{2}$ sensitivity which can all affect the circulating current path and hence the EP.

In conclusion, these studies show that $\mathrm{CO}_{2}$ and $\mathrm{HCO}_{3}{ }^{-}$ each play an important role in establishing cochlear fluids $\mathrm{pH}$ and may thereby influence many aspects of ion transport and cochlear function. As $\mathrm{HCO}_{3}^{-}$represents a significant component of both endolymph and perilymph, it is important to detail the mechanisms underlying its homeostasis, in order to understand how the cochlear fluids are maintained in normal and pathological states.

\section{CONFLICT OF INTEREST}

This was not an industry-supported study. Authors have no conflicts of interest to declare in relation to the subject matter of this manuscript.

\section{ACKNOWLEDGEMENTS}

Authors would like to express their appreciation for Dr. Alec N. Salt, Department of Otolaryngology, Washington University in St. Louis, MO, USA, for his guidance.

\section{REFERENCES}

[1] Hruska K. The kidney and body fluids in health and disease. In: Klahr S, Ed. Pathophysiology of acid-base metabolism. New York: Plenum Press 1983; pp. 223-67.

[2] Suzuki M, Salt AN. Regulation of cochlear fluids pH: (1) The role of carbon dioxide. TOOTORJ 2014 (in review: companion paper)

[3] Wietasch K, Kraig RP. Carbonic acid buffer species measured in real time with an intracellular microelectrode array. Am J Physiol 1991; 261: R760-65.

[4] Konishi T, Kelsey E. Effect of potassium deficiency on cochlear potentials and cation contents of the endolymph. Acta Otolayryngol 1973; 76: 410-8.

[5] Ikeda K, Kusakari J, Takasaka T, Saito Y. Early effects of acetazolamide on ionic activities of the guinea pig endolymph: Evidence for active function of carbonic anhydrase in the cochlea. Hear Res 1987; 31: 211-6.

[6] Isaacs JH Jr, Pessah N, Merwin GE, Maren TH. Lack of effect of carbonic anhydrase inhibition on direct measurements of endolymph bicarbonate. Ann Otol Rhinol Laryngol 1989; 98: 20912.

[7] Wangemann P, Liu J, Shiga N. The pH-sensitivity of transepithelial $\mathrm{K}^{+}$transport in vestibular dark cells. J Membrane Biol 1995; 147: 255-62.

[8] Suzuki M, Kikuchi T, Ikeda K. Endocochlear potential and endolymphatic $\mathrm{K}$ changes induced by gap junction blockers. Acta Otolaryngol 2004; 124: 902-6.

[9] Ammann D, Lanter F, Steiner RA, Schulthess P, Shijo Y, Simon W. Neutral carrier based hydrogen ion selective microelectrode for extra-and intracellular studies. Anal Chern 1981; 53: 2267-9.

[10] Salt AN, Vora AR. Cochlear threshold assessment using tonederived action potentials. Audiology 1990; 29: 135-45.

[11] Chesler M, Chen JC, Kraig RP. Determination of extracellular bicarbonate and carbon' dioxide concentrations in brain slices using carbonate and pH-selective microelectrodes. Neurosci Meth 1994; 53: $129-36$

[12] Bobbin RP, Fallon M, Kujawa SG. Magnitude of negative summating potential varies with perilymph calcium levels. Hear Res 1991; 56: 101-10.

[13] Kujawa SG, Fallon M, Bobbin RP. ATP antagonists cibacron blue, basilen blue and suramin alter sound-evoked responses of the cochlea and auditory nerve. Hear Res 1994; 78: 181-8.

[14] Klis SF, Smoorenberg GF. Osmotically induced pressure difference in the cochlea and its effect on cochlear potentials. Hear Res 1994; 75: $114-20$

[15] Salt AN, Stopp PE. The effect of raising scala tympani potassium concentration on ton-induced cochlear responses of the guinea pig. Exp Brain Res 1979; 36: 87-98.

[16] Zidanic M, Brownell WE. Fine structure of the intracochlear potential field. I. The silent current. Biophys J 1990; 57: 1253-68.

[17] Salt AN, DeMott JE. Longitudinal endolymph movements induced by perilymphatic injections. Hear Res 1998; 123: 137-47.

[18] Arakawa E, Marcus DC, Thalmann R. Dependence of endocochlear potential on vascular pH. Hear Res 1987; 31: 1-7. 